\title{
УСЛУГА КАК ОБЪЕКТ ДОГОВОРА ТЕХНОЛОГИЧЕСКОГО ПРИСОЕДИНЕНИЯ К ЭЛЕКТРИЧЕСКИМ СЕТЯМ
}

\section{SERVICES AS A SUBJECT OF THE TECHNOLOGICAL CONNECTION CONTRACT}

\section{A. Vasev}

Summary: Researching questions of the issue of key features of a service as an object of an agreement, as an object of legal relations arising from the technological connection contract. It is proved that that the main feature of a service as an object of a contract is its inseparability from the contractor and customer of the service. It is concluded that a service is an economic benefit, which is a set of actions of one person to meet the needs of another person.

Keywords: technological connection contract, service contracts, services, subject matter of the contract, economic benefit, service signs.
$\mathrm{B}$ современной юридической науке дискуссионным является вопрос о правовой природе договора технологического присоединения к электрическим сетям. На сегодняшний день единой позиции в научном сообществе нет. Развитие судебной практики, а также работы отдельных авторов доказательно и непротиворечиво приводят к выводу, что договор технологического присоединения по своей правовой природе является видом договора возмездного оказания услуг.

Развитие современного мира, переход к постиндустриальному обществу приводят к увеличению внимания цивилистов к проблематике исследования услуг как объекта гражданских прав. На важность исследования услуги не только как объекта гражданских прав, но и как экономического блага указывают многие исследователи. В современной юридической науке дискуссионным остаётся вопрос об определении сущностных признаков услуги, которые являются ключевыми в отграничении данного вида блага от других.

Важным является охарактеризовать услугу как объект договора, как объект правоотношений, возникающих из договора технологического присоединения к электрическим сетям, а также определить сущностные признаки услуги, отличающие её от иных видов объектов гражданских прав.

Под объектом гражданских прав следует понимать материальные и нематериальные блага, по поводу которых возникают субъективные гражданские права и
Васёв Артём Александрович

Аспирант, Пермский государственный национальный исследовательский университет vasev.aa@mail.ru

Аннотация: В статье рассматривается вопрос о ключевых признаках услуги как объекта договора, как объекта правоотношений, возникающих из договора технологического присоединения к электрическим сетям. Доказано, что главным признаком услуги как объекта договора является её неотделимость от исполнителя и заказчика услуги. Сделан вывод о том, что под услугой понимается экономическое благо, которое представляет собой совокупность действий одного лица по удовлетворению потребности другого лица.

Ключевые слова: договор технологического присоединения, договор возмездного оказания услуг, услуги, объект договора, экономическое благо, признаки услуги.

обязанности [3]. Необходимо определить, что понимается в современной юридической науке под категорией «благо». Согласно позиции К.С. Козловой под «благом» понимается положительная ценность, предмет явление, которое удовлетворяет ту или иную человеческую потребность [5]. В философии благо понимается как наиболее общее понятие для обозначения положительной ценности.

Для экономической сферы жизни общества формируется свой вид благ - экономические (имущественные). А. Маршалл под благом понимал «все желаемые нами вещи или вещи, удовлетворяющие человеческие потребности» $[17$, с. 19]. В этом контексте определение «блага» ограничено вещами или предметами. Отнесение того или иного предмета к категории блага возможно при соблюдении определенных критериев.

В частности, согласно позиции К. Мегнера должны выполняться одновременно следующие четыре условия: наличие человеческой потребности; определенные свойства объекта, которые делают его пригодным для удовлетворения этой потребности; познание человеком этой причинной связи (между потребностью и объектом, который должен удовлетворить потребность); возможность распорядиться объектом таким образом, чтобы действительно употребить его для удовлетворения этой потребности.

К. Мегнер также определяет категорию благ, которые в современном ему научном сообществе объединяются 
в особую категорию под названием «отношения», видом которых являются услуги [12, с. 62]. Любые виды блага, в том числе услуги, призваны удовлетворять потребности субъектов отношений. Целью экономической деятельности человека является получение полезного результата и удовлетворение потребностей, как себя, так и других людей [16].

С точки зрения вещественного содержания блага делятся на материальные и нематериальные. К последним, в частности, относятся услуги. В российской научной литературе отличие услуги от материальных благ определяется через признаки потребляемости услуги в момент её оказания, а также невозможности накопления и сохранения услуг [6].

И.Д. Котляров указывает на недостаток современного уровня исследований, поскольку в современной науке отсутствует единое определение понятия услуги как экономического блага [8]. Большинство авторов рассматривает услугу с точки зрения противопоставления её сущности товару из-за специфической природы услуги как выполняемого действия.

Определение услуги через ее отделение от остальных экономических благ и противопоставление им, их вычитанием из общей совокупности экономических благ применимо в том случае, когда отсутствует возможность однозначно идентифицировать хозяйственную деятельность как продуцирующую материальные блага [13].

С точки зрения экономической теории услугу можно определить как «блага, представленные не в форме вещей, а в форме деятельности» [9, с. 368]. Услуга чаще определяется через её активную составляющую - деятельность исполнителя. В таком контексте услуга представляет собой деятельность, которая направлена на удовлетворение потребностей других лиц на основе договорных отношений между производителем и потребителем услуги [13].

По мнению Д.Г. Поповой разработка цивилистического доктринального понятия услуги позволит провести систематизацию гражданско-правовых обязательств, выделив среди них обязательства об оказании работ и обязательства об оказании услуг. Автор разделяет экономический подход к определению понятия услуги и правовой подход. С экономической точки зрения услуги можно подразделять на материальные, обеспечивающие восстановление, изменение, сохранение потребительских свойств изделий или изготовление новых изделий, а также перемещение грузов и людей, создание условий для потребления, и нематериальные по удовлетворению духовных, интеллектуальных потребностей и поддержанию нормальной жизнедеятельности потребителя. Последний вид услуг, не имеющих материально- го выражения, автор относит к виду социокультурных услуг [14].

С правовой точки зрения услуги отграничиваются от работ, поскольку в процессе выполнения работы для целей правового регулирования важен результат (завершение работы), а для услуги - важно действие исполнителя, завершение и результат которого нельзя квалифицировать как товар или как результат той или иной работы [10, с. 5-7].

Д.А. Карх разделяет все определения услуги на три вида: первые характеризуют услугу как действия, виды деятельности и непосредственно саму деятельность; вторые под услугой понимают уже полученный результат деятельности, третий вид определений комплексно характеризует услугу как деятельность и как результат такой деятельности [4, с. 89].

Большинство авторов определяют услугу через её выражение в активной форме - а именно в действиях исполнителя [15]. Действия исполнителя, составляющие услугу, имеют цель удовлетворять потребность лица, в пользу которого они совершается. Лицо, в интересах которого осуществляется услуга, в большинстве договоров возмездного оказания услуг, так или иначе, выполняет определенные соглашением сторон фактические действия, которые обеспечивают возможность оказания услуги. Например, по договору технологического присоединения к электрическим сетям заявитель обязан осуществить мероприятия, предусмотренные техническими условиями подключения, в пределах границ своего земельного участка.

Услуга как экономическое благо представляет собой совокупность действий одного лица (исполнителя) по удовлетворению потребности другого лица (потребителя услуги / заказчика). Любой вид услуги обладает двумя ключевыми признаками: неосязаемости и интегративности (одновременности производства и потребления).

Согласно позиции Ф. Котлера услуга представляет собой «деятельность или благо, которую одна сторона предлагает другой, и которая по своей сути является неосязаемой и не связана с передачей собственности» [7, с. 718]. В том или ином обязательстве, предметом которого является услуга, обязанности исполнителя могут включать не только совершение определенных действий в интересах заказчика, но и представление заказчику определенного результата таких действий [11].

На сегодняшний день многие авторы, занимающиеся исследованием договора возмездного оказания услуг, указывают на необходимость определения результата услуги. Действия исполнителя, составляющие услугу, имеют своей непосредственной целью удовлетворение 
потребностей лица, в пользу которого они совершаются.

При этом чтобы удовлетворить потребность, этот процесс должен иметь некий результат, который будет пригоден для потребления заказчиком [2]. Результат оказания услуги, таким образом, выражается в достигаемом «эффекте услуги» [1]. Услуга как вид экономического блага своим результатом имеет удовлетворение потребности заказчика услуги.

Важно отличать понятие неосязаемости и нематериальности для характеристики услуги. При оказании услуги исполнителем могут быть задействованы материальные ресурсы, у услуги может быть материализованный результат, но в большинстве случаев услуга состоит в осуществлении действий, которые являются неосязаемыми. Вместе с тем, И.Д. Котляров, анализируя критерий неосязаемости услуги, указывает, что информация, являясь товаром, также является неосязаемой [8].

Одновременность производства и потребления также не всегда может быть свойственна исключительно услуге как виду блага и объекту гражданских прав. И.Д. Котляров указывает, что существуют и товары, момент производства и потребления которых совпадает, например, электроэнергия [8].

Другой анализируемый признак - неотделимость услуги от исполнителя и заказчика услуги. Неотделимость услуги означает сотрудничество субъектов рассматриваемых отношений в процессе оказания услуги, а не их постоянное «живое» взаимодействие (представляющее собой частный случай сотрудничества). Целью такого сотрудничества является создание блага для потребителя услуги [1, с. 55].

Полагаем, что указанный признак представляется отличительным для характеристики услуги как вида экономического блага. При этом важно отметить, что отдельные авторы совершают ошибку и отождествляют понятие неотделимости с непосредственным физическим контактом, указывая на различные способы дистанцион- ного взаимодействия исполнителя с заказчиком. Услуги, бесспорно, могут оказываться в дистанционном формате, но, тем не менее, услуга всегда будет неотделима от субъектов отношений.

Услуга, состоящая из активных действий исполнителя, направленных на удовлетворение потребности заказчика услуги, ключевой характеристикой имеет свою неотделимость от субъекта. В данном контексте услуга без субъекта существовать не может. Если материальная вещь может существовать без субъекта (в качестве примера можно привести институт бесхозяйных вещей), то услуга как вид экономического блага всегда связана с активным субъектом - исполнителем. Важно отметить, что услуга также не может существовать и без заказчика услуги, поскольку целью любой услуги является удовлетворение потребности, интереса заказчика.

Можно сделать вывод о том, что под услугой понимается экономическое благо, которое представляет собой совокупность действий одного лица (исполнителя) по удовлетворению потребности другого лица (потребителя услуги / заказчика). Сущностным признаком услуги является её неотделимость от исполнителя и заказчика услуги, поскольку исполнитель - является активным субъектом, который непосредственно оказывает услугу, а удовлетворение потребности заказчика является ключевой сущностной целью услуги. Следовательно, без субъектов услуга как благо существовать не может.

Предметом договора технологического присоединения как вида договора возмездного оказания услуг являются действия исполнителя (сетевой организации) по подключению объекта заявителя к своей электрической сети. Объект договора составляет услуга по технологическому присоединению. При этом под технологическим присоединением следует понимать комплекс мероприятий, целью которых является обеспечение возможности потребления и передачи электроэнергии, что, в конечном счете, с точки зрения выводов настоящей статьи является удовлетворением потребности заказчика услуги.

\section{ЛИТЕРАТУРА}

1. Боков В.И. От Даля к Парсонсу и обратно. Гипотеза о природе услуги // Социологические исследования. 2003. № 7. С. 49 - 56.

2. Вольвач Я.В. 0 необходимости гражданско-правового регулирования вопросов качества услуг // Адвокат. 2013. № 5. Доступ из СПС «КонсультантПлюс».

3. Гончарова А.В. Сравнительный анализ объектов гражданских прав и объектов гражданских правоотношений // Вестник ВолГУ. Серия 5: Юриспруденция. 2016. №4 (33). URL: https://cyberleninka.ru/article/n/sravnitelnyy-analiz-obektov-grazhdanskih-prav-i-obektov-grazhdanskih-pravootnosheniy (дата 0бращения: 23.12.2019).

4. Карх Д.А. Теоретические основы развития сущности услуг // Вестник Южно-Уральского государственного университета. Серия «Экономика и менеджмент». 2010. № 7. С.89- 91.

5. Козлова К.С. Категория «Благо»: от философско-этического к экономическому и политико-правовому смыслам // 0HB. 2012. №3 (109). URL: https:// cyberleninka.ru/article/n/kategoriya-blago-ot-filosofsko-eticheskogo-k-ekonomicheskomu-i-politiko-pravovomu-smyslam (дата обращения: 15.01.2020).

6. Косов Н.С. Основы макроэкономического анализа: учебное пособие. 2006 // URL: https://laws.studio/knigi-makroekonomika/ekonomicheskie-blaga- 
klassifikatsiya-68483.html (дата обращения: 15.01.2020).

7. Котлер Ф. и др. Основы маркетинга. М.:1998. 1056 с.

8. Котляров И.Д. Сущность услуги как экономического блага // Вестник ОмГУ. Серия: Экономика. 2012. №3. URL: https://cyberleninka.ru/article/n/suschnostuslugi-kak-ekonomicheskogo-blaga-1 (дата обращения: 22.01.2020).

9. Лопатников, Л.И. Экономико-математический словарь / Л.И. Лопатни-ков. - М.: Наука, 1993.

10. Манохин, В. М. Хозяйственное обслуживание организаций и граждан (организационно-правовые вопросы) / В. М. Манохин. - М.: Юридическая литература, 1975. 224 C.

11. Мартиросова Л.Э. Оказание услуг как объект гражданских прав // Инновационная наука. 2016. №8-3. URL: https://cyberleninka.ru/article/n/okazanieuslug-kak-obekt-grazhdanskih-prav (дата обращения: 15.02.2020).

12. Менгер К. Избранные работы / К. Менгер. М.: Территория будущего, 2005. 496 с.

13. Перепелкин В.А. Понятие «Услуга» в экономической теории // Вестник СамГУ. 2009. №69. URL: https://cyberleninka.ru/article/n/ponyatie-usluga-vekonomicheskoy-teorii (дата обращения: 24.03.2020).

14. Попова Д.Г. Услуга как объект гражданских прав и ее соотношение с категорией «Социальная услуга» // Вестник КемГУ. 2012. №1. URL: https:// cyberleninka.ru/article/n/usluga-kak-obekt-grazhdanskih-prav-i-ee-sootnoshenie-s-kategoriey-sotsialnaya-usluga (дата обращения: 14.03.2020).

15. Степанов Д. Услуги как объект гражданских прав // Российская юстиция. 2000. № 2. Доступ из СПС «КонсультантПлюс».

16. Чернявский А.Д. Услуга как частная форма экономического блага // Экономическая наука и практика: материалы Междунар. науч. конф. (г. Чита, февраль 2012 г.). Чита: Издательство Молодой ученый, 2012. URL https://moluch.ru/conf/econ/archive/14/1609/ (дата обращения: 22.03.2020).

17. Экономика труда 3-е изд., пер. и доп. Учебник и практикум для академического бакалавриата / под ед. Ю.Г. Одегова, Г.Г. Руденко. М.: 2015.386 с.

(с) Васёв Артём Александрович (vasev.aа@mail.ru).

Журнал «Современная наука: актуальные проблемы теории и практики»

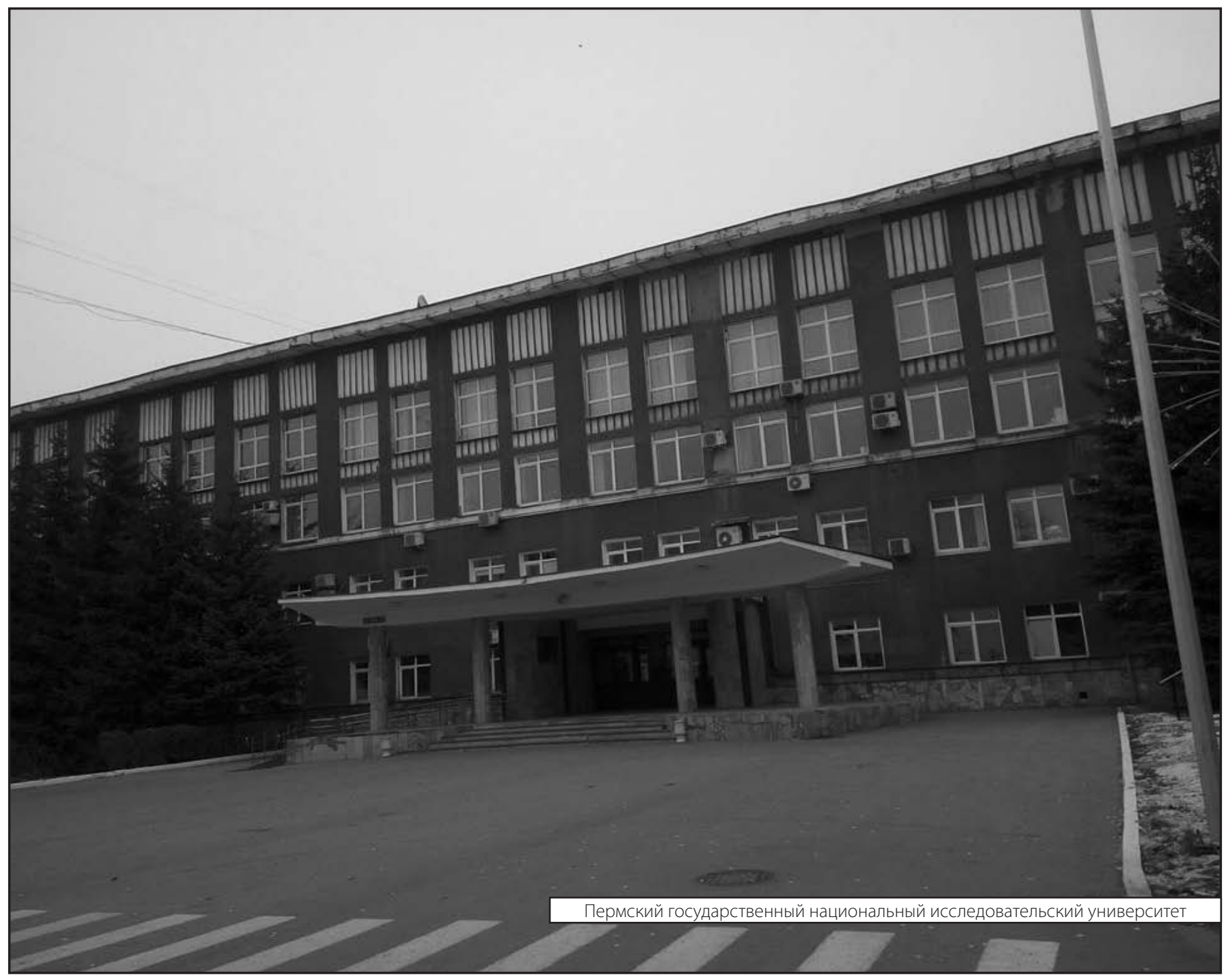

